\title{
Why people matter in ocean governance: Incorporating human dimensions into large-scale marine protected areas
}

Patrick Christie ${ }^{a, b, *}$, Nathan J. Bennett ${ }^{a, c, l}$, Noella J. Gray ${ }^{f}$, T. 'Aulani Wilhelm ${ }^{m, n}, N^{\prime} i^{\prime a}$ Lewis $^{o, p}$, John Parks ${ }^{d}$, Natalie C. Ban ${ }^{e}$, Rebecca L. Gruby ${ }^{g}$, Lindsay Gordon ${ }^{a}$, Jon Day ${ }^{h}$, Sue Taei ${ }^{i}$, Alan M. Friedlander,k

a School of Marine and Environmental Affairs, University of Washington, Seattle, WA, United States

b Jackson School of International Studies, University of Washington, Seattle, WA, United States

c Institute for Resources, Environment and Sustainability, University of British Columbia, Canada

${ }^{d}$ Marine Management Solutions, Honolulu, HI, United States

e School of Environmental Studies, University of Victoria, Australia

${ }^{f}$ Department of Geography, University of Guelph, Canada

g Department of Human Dimensions of Natural Resources, Colorado State University, United States

${ }^{\mathrm{h}}$ ARC Centre of Excellence for Coral Reef Studies, James Cook University, Australia

' Conservation International, Pacific Islands Program, New Zealand

j Pristine Seas, National Geographic Society, Washington, DC, United States

${ }^{k}$ Fisheries Ecology Research Laboratory, University of Hawai'i, Honolulu, HI, United States

' Center for Ocean Solutions, Stanford University, United States

${ }^{m}$ Conservation International Center for Oceans, Honolulu, USA

n Big Ocean, Honolulu, USA

○ 84 and Sunny, Honolulu, USA

p International Union for the Conservation of Nature Large-Scale MPA Task Force, Gland, Switzerland

*Corresponding author at: School of Marine and Environmental Affairs, University of Washington, 3707 Brooklyn Ave NE, Seattle, WA 98105-6715, USA.

This is the accepted manuscript of an article published in Marine Policy. The final version may be accessed at https://dx.doi.org/10.1016/j.marpol.2017.08.002. 


\section{Abstract}

Large-scale marine protected areas (LSMPAs) are rapidly increasing. Due to their sheer size, complex sociopolitical realities, and distinct local cultural perspectives and economic needs, implementing and managing LSMPAs successfully creates a number of human dimensions challenges. It is timely and important to explore the human dimensions of LSMPAs. This paper draws on the results of a global "Think Tank on the Human Dimensions of Large Scale Marine Protected Areas" involving 125 people from 17 countries, including representatives from government agencies, non-governmental organizations, academia, professionals, industry, cultural/indigenous leaders and LSMPA site managers. The overarching goal of this effort was to be proactive in understanding the issues and developing best management practices and a research agenda that address the human dimensions of LSMPAs. Identified best management practices for the human dimensions of LSMPAs included: integration of culture and traditions, effective public and stakeholder engagement, maintenance of livelihoods and wellbeing, promotion of economic sustainability, conflict management and resolution, transparency and matching institutions, legitimate and appropriate governance, and social justice and empowerment. A shared human dimensions research agenda was developed that included priority topics under the themes of scoping human dimensions, governance, politics, social and economic outcomes, and culture and tradition. The authors discuss future directions in researching and incorporating human dimensions into LSMPAs design and management, reflect on this global effort to co-produce knowledge and re-orient practice on the human dimensions of LSMPAs, and invite others to join a nascent community of practice on the human dimensions of large-scale marine conservation.

\section{Introduction}

A new era in marine conservation has emerged. Within the international conservation arena, there has long been a sustained effort to promote marine protected areas (MPAs) as a preferred marine conservation policy tool [1]. Through conventions and other efforts (e.g., Resolution of 17th Assembly of IUCN in 1987; the United Nations (UN) Earth Summit in 1992; the World Parks Congress in 2003; the Aichi Targets from the tenth meeting of the UN Convention of Biological Diversity Conference of Parties (COP 10); the World Parks Congress in 2014), the international community has agreed on several conservation targets, most notably aspiring to set-aside between $10-30 \%$ of the world's oceans in MPAs [2,3]. While setting such targets has not been without its critics [4-7], there has been rapid and increasing growth in the number and spatial extent of MPAs globally. Yet large-scale marine protected areas (LSMPAs) are a relatively new phenomenon.

Similarly to Toonen et al. [8] and as employed by the Big Ocean network of LSMPAs managers, LSMPAs are defined as areas nearly 100,000 miles $^{2}$ or more in size (i.e., roughly $250,000 \mathrm{~km}^{2}$ or more). This definition is significantly larger than the median size of $3.3 \mathrm{~km} 2$ of more than 6000 MPAs established globally by 2013 [9]. Others have defined LSMPAs in different ways - e.g., as larger than $30,000 \mathrm{~km}^{2}$ [3] or $100,000 \mathrm{~km}^{2}[10,11]$. The results presented in this article are relevant to all large-scale conservation efforts. In recent years, LSMPAs have offered the largest spatial contributions to meeting international ocean protection targets [8,9]. While Wood et al. 
[2] projected that the $10 \%$ target would not be achieved until 2067 , more recent establishment of LSMPAS suggest that the 10\% global MPA target may be attainable by c.2035 [9].

Large-scale MPAs originated in 1975, when the Great Barrier Reef Marine Park Act established the Great Barrier Reef Marine Park (GBRMP), measuring 344,400 km². The multiple-use GBRMP remained the largest MPA on the planet for 23 years and has continued to serve as an example of the potential of large-scale marine conservation for many subsequent MPA efforts worldwide [12-14]. Then in 1998, the Galapagos Marine Reserve was created by Ecuador and in 2000 United States President Clinton created the Northwestern Hawaiian Islands Coral Reef Ecosystem Reserve and in 2001 initiated the process to designate a National Marine Sanctuary (Executive Orders 13178 and 13196). In March 2006 Kiribati declared the Phoenix Islands Protected Area (PIPA) and expanded it in 2008 to $408,250 \mathrm{~km}^{2}$ in its full legal gazettement. In June 2006, using the U.S. Antiquities Act, U.S. President George W. Bush designated the Northwestern Hawaiian Islands as the Papahānaumokuākea Marine National Monument (PMNM). Both PIPA and PMNM were later recognized as UN World Heritage sites in 2010 [15]. At the time, PMNM and PIPA were two of the largest MPAs in the world, and their establishment sparked a new era of large-scale ocean and island conservation, significantly remote and different from the coastal nature of GBRMPA. As the world's largest MPA (at the time) created by a small island developing nation, PIPA inspired the Pacific Island Forum Leaders' Framework for a Pacific Oceanscape and subsequent large scale Pacific Island designations. Together PMNM and PIPA as sister sites convened the first learning network for LSMPAs-the Big Ocean network.

Since just 2009, many new LSMPAs larger than 250,000 km2 have been declared or existing MPAs have been expanded to this scale [see Table 1 and Fig. 1]. Additional sites have been proposed or declared and are in various stages of development including Marae Moana (Cook Islands, 1,900,000 $\mathrm{km}^{2}$ ), Coral Sea Commonwealth Marine Reserve (Australia, 989,842 km²), Te Tau Nui a Hau MPA (French Polynesia, 700,000 km²), Kermadec Ocean Sanctuary (New Zealand, $620,000 \mathrm{~km}^{2}$ ), Ascension Island MPA (United Kingdom, 445,390 km²) and Tristan da Cunha MPA (United Kingdom, 750,510 $\mathrm{km}^{2}$ ). At the time of this writing, more LSMPAs have been proposed by governments and non-governmental organizations (NGOs).

One reason for the emphasis on MPAs as a conservation tool, including in international targets, is because of their demonstrated effectiveness in achieving ecological benefits. MPAs have been shown to increase target species inside their boundaries, enhance fisheries in adjacent waters via adult spillover and increased reproductive output, while also protecting critical habitats $[16,17]$. LSMPAs have the potential to provide added fisheries and ecological value relative to smaller MPAs by protecting entire ecosystems, particularly habitats not typically part of nearshore MPAs, such as the deep sea, seamounts, and pelagic realms [18-20]. In addition, LSMPAs directly protect highly mobile species such as tunas, billfish, sharks and other targeted fisheries species, as well as sea turtles, marine mammals, seabirds and other pelagic species, which are taken as by-catch in pelagic fisheries [8]. 
Despite the proliferation of LSMPAs, they come with unique social, political, cultural, and economic opportunities and challenges that are poorly understood. First, past research has suggested that management of LSMPAs might be more cost efficient than smaller areas [21]. Yet, there is a very real danger that these LSMPAs will simply be "paper parks" due to lack of resources or capacity to take management actions, monitor or enforce regulations [3,22]. While recent years have seen significant advances and enthusiasm about the potential for technology to aid with monitoring - including drones and satellite data - the will and ability to subsequently enforce restrictions is hampered by costs, operational limitations, policy loopholes, and pressure from the fishing and mining industries $[23,24]$. Second, Gruby et al. [10] identify a number of important political and governance considerations, including questions about which groups (e.g., NGOs, philanthropic organizations, the private sector, foreign states, national governments, political elites, local people) and what underlying interests (e.g., conservation, fisheries, geopolitics, sovereignty) are driving the process of creating and managing LSMPAs [3,25]. Finally, ensuring equitable distribution of the costs and benefits of LSMPAs to local people and national economies presents both challenges and opportunities [26]. There is the potential for lost economic benefits or opportunities for the fishing and mining sectors, which may form a significant portion of the economy of some countries [10]. LSMPAs may displace or reduce fishing effort, and their contribution to alleviating global issues of overfishing and impacts on associated species is yet to be fully understood [27]. Having received significant attention in the literature on smaller MPAs, the socio-economic impacts of conservation and the displacement of small-scale fishers and indigenous communities from LSMPAs is an additional important ethical and socio-economic consideration [28-30]. On the other hand, LSMPAs also provide unique opportunities to protect cultural heritage and the resources upon which livelihoods are based [31,32].

In 2010, in recognition of the unique management challenges and significant opportunities of LSMPAs, Big Ocean, a peer-to-peer network of managers of LSMPAs, was created with the purpose of developing and enhancing the professional standards of practice, and long-term, effective management of LSMPAs through peer-learning (see http://bigoceanmanagers.org). As one of its inaugural efforts, the Big Ocean network of managers and scientists gathered at a three-day think tank in 2011 [8] to develop a bio-physical research agenda for LSMPAs [33]. Three main research themes emerged from this effort: (1) biological and ecological characterization, (2) connectivity, and (3) monitoring of temporal trends. The intention was to provide a framework to help facilitate future joint research efforts between Big Ocean sites, and thereby improve marine management practices worldwide as additional LSMPAs are proposed and established.

Given the rapid and recent growth in designation of LSMPAs and the potential challenges and opportunities associated with their creation and ongoing management, it is both timely and important to explore the human dimensions (HD) of LSMPAs. While interest in the HD of conservation has grown, there remains a surprising lack of full engagement with HD recommendations in conservation practice in general [34,35] and in LSMPAs in particular [10]. Three reasons emerge to explain this oversight. First, the leading paradigm of conservation practice still privileges scientific ecological knowledge and priorities over human dimensions 
[34]. Yet, research on conservation, MPAs and fisheries management effectiveness consistently highlight that HD considerations are central to the success of conservation [28-30,36-39]. Furthermore, as Richmond \& Kotowicz [26] show, not incorporating social, economic and cultural considerations into LSMPAs can lead to significant conflict and resistance. Second, the inclusion of both relevant (natural and social) scientific and non-scientific knowledge into the planning process is challenging $[40,41]$. Third, the objectives and institutional cultures of academic social sciences and conservation organizations are not always well matched - with the former valuing theory development and peer reviewed publications and the latter being more interested in practical knowledge. To bridge these two worlds, the authors believe that institutional innovation - for example, in the form of boundary organizations, bridging institutions and communities of practice-is essential to simultaneously improve both understanding of the human dimensions and the incorporation of these considerations into conservation practice.

To help overcome these impediments, the authors convened an international "Think Tank on the Human Dimensions of Large Scale Marine Protected Areas" (hereafter the HD Think Tank) which involved more than 125 researchers and practitioners from around the globe. This paper draws on the results of this international knowledge coproduction exercise to: 1) critically review the current understanding of the HD of LSMPAs; 2 ) examine diverse perspectives on existing HD knowledge related to LSMPAs; 3 ) develop practical recommendations and identify best management practices regarding HD considerations in LSMPAs; 4) produce a shared HD research agenda for LSMPAs; and, 5) launch a community of practice focusing on the HD of LSMPAs. This paper presents results from this meeting, reflects on this global effort to coproduce knowledge and re-orient conservation practice, and identifies next steps for moving a community of practice on the HD of LSMPAs forward. 


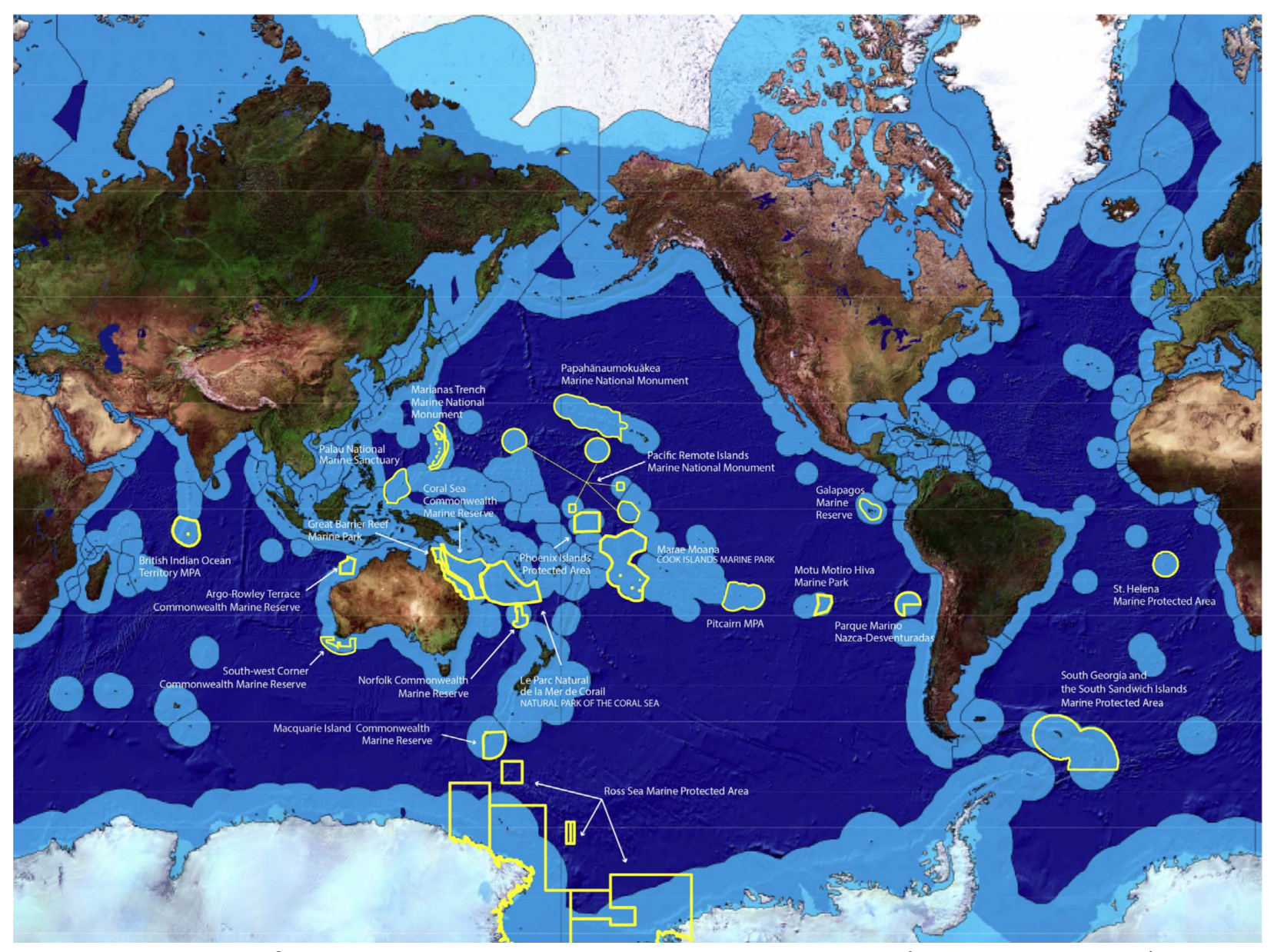

Fig. 1. Global map of established large-scale marine protected areas (Source: Big Ocean). 
Table 1. Established large-scale marine protected areas (listed by date of establishment, as of January 2016) .

\begin{tabular}{|c|c|c|c|}
\hline Name and Type of LSMPA & Country & Year & Area $\left(\mathrm{km}^{2}\right)$ \\
\hline 1. Great Barrier Reef Marine Park & Australia & 1975 & 344,400 \\
\hline 2. Galapagos Island Marine Reserve & Ecuador & 1998 & 133,000 \\
\hline 3. Papahānaumokuākea Marine National Monument & United States & $\begin{array}{l}\text { (2006 } \\
\text { established) } \\
2016 \text { Expansion }\end{array}$ & $\begin{array}{l}(362,075) \\
1,508,870\end{array}$ \\
\hline 5. Phoenix Islands Protected area & Kiribati & $\begin{array}{l}\text { (2006 } \\
\text { Established) } \\
2008 \text { expansion }\end{array}$ & $\begin{array}{l}(184,700) \\
408,250\end{array}$ \\
\hline 7. Marianas Trench Marine National Monument & United States & 2009 & 250,487 \\
\hline 8. Pacific Remote Islands Marine National Monument & United States & $\begin{array}{l}\text { (2009 } \\
\text { Established) } \\
2014 \text { Expansion }\end{array}$ & $1,269,065$ \\
\hline 10. Motu Motiro Hive Marine Park & Chile & 2010 & 150,000 \\
\hline 11. British Indian Ocean Territory Marine Reserve & United Kingdom & 2010 & 640,000 \\
\hline 12. South-west Corner Commonwealth Marine Reserve & Australia & 2012 & 271,898 \\
\hline 13. Norfolk Commonwealth Marine Reserve & Australia & 2012 & 188,433 \\
\hline 14. Macquarie Island Commonwealth Marine Reserve & Australia & 2012 & 162,000 \\
\hline 15. Argo-Rowley Terrace Commonwealth Marine Reserve & Australia & 2012 & 146,099 \\
\hline 16. South Georgia \& the South Sandwich Islands MPA & United Kingdom & 2013 & $1,007,000$ \\
\hline 17. Le Parc Naturel de la Mer de Corail (National Park) & France & 2014 & $1,300,000$ \\
\hline 18. Palau National Marine Sanctuary & Palau & 2015 & 500,238 \\
\hline 19. Parque Marino Nazca-Desventuradas (Marine Park) & Chile & 2015 & 297,518 \\
\hline 20. Pitcairn Islands Marine Reserve & United Kingdom & 2016 & 840,000 \\
\hline 21. St. Helena Marine Protected Area & United Kingdom & 2016 & 444,916 \\
\hline 22. Ross Sea Marine Protected Area & $\begin{array}{l}\text { International } \\
\text { waters }\end{array}$ & 2016 & $1,550,000$ \\
\hline 23. Marae Moana: Cook Islands Marine Park & Cook Islands & 2017 & $1,900,000$ \\
\hline Approximate Total Area & & & $13,312,174$ \\
\hline
\end{tabular}

${ }^{a}$ In consideration of other LSMPA analyses and participation in the Big Ocean network, sites less than $250,000 \mathrm{~km}^{2}$ are included in this table and subsequent map.

\section{Methods}

Recognizing the need for institutional innovation to facilitate real-world change, the authors undertook an action research and knowledge co-production exercise to begin the process of developing best practices for incorporating HD into LSMPA design and management. Action research refers to research processes that are participative and bridge knowledge creation with action taking in pursuit of solutions to issues that are of concern to those involved [42]. One of the main aims of action research is knowledge co-production, a term that refers to a "process of producing usable, or actionable, science through collaboration between scientists and those who use science to make policy and management decision" [43]. Both action research and knowledge co-production require collaboration at all stages, including framing the questions, designing the research, collecting data, analyzing results, creating outputs and implementation of recommendations $[34,41,43]$. Our approach was to convene a three-day think tank on the HD of LSMPAs in Honolulu, Hawaii from Feb 8-10, 2016. The design team that organized the think-tank (which included five academics from US and Canadian universities, two leads of Big Ocean and two LSMPA managers) met approximately once a month during the year leading up 
to the event. A professional facilitator (John Parks, Marine Management Solutions) was hired to help plan and facilitate the think tank. Funding was raised from various non-profit environmental and government sources (see Acknowledgements). The authors designed the HD Think Tank so that it was participatory and action-oriented. The authors also saw the HD Think Tank as an opportunity to launch a community of practice - a term which refers to "groups of people who share a concern or a passion for something they do and learn how to do it better as they interact regularly" [44] - to promote the development, sharing and implementation of knowledge related to the HD of LSMPAs $[45,46]$.

To ensure a broad array of expertise and diverse organizational affiliations in the HD Think Tank and emergent community of practice, a critical and complex step in the design process was to identify participants who were in some way involved in the creation, management, or study of human dimension of LSMPAs from diverse geographies, disciplinary backgrounds, and sectoral perspectives. The HD Think Tank brought together 125 individuals from around the world, including site managers (from existing and proposed LSMPA sites), NGO partners, academics (including professors, researchers and students), professionals (including lawyers, consultants, etc.), government, community and cultural leaders, and industry representatives engaged in the subject (see Appendix A). Site managers, NGO representatives and academics were well represented; however, a limitation was the insufficient representation from local NGOs, community groups, fisheries groups, governments and industry.

Prior to the HD Think Tank, the authors surveyed the participants and experts in the HD of MPAs using Survey Monkey to learn more about their perspectives on human dimension challenges, successes, research needs, opportunities, and next steps for creating a community of practice on these issues [see Supplementary Materials - Appendix A]. This information shaped the HD Think Tank agenda. From a total of 213 invitations, a total of 102 people (48\% response rate) responded to the survey. Respondents included representatives from the following groups: coastal and marine management specialists ( $24 \%$ of respondents), nongovernmental organizations (NGOs; 7\%), academia (33\%), professionals (lawyers, consultants; $5 \%)$, other (including industry (3\%), fisheries \& tourism; 16\%), cultural/indigenous leaders (5\%) and LSMPA site managers (10\%). The sampling for this survey was not randomized and results are not generalizable.

In the meeting [see Supplemental Materials - Appendix B], the authors used a variety of facilitation strategies (e.g., break out groups, plenary discussions, knowledge cafés, etc.) and guiding questions to co-characterize the problem(s), co-identify future research questions and projects and co-create outputs from the think tank. At the beginning of each day of the HD Think Tank, diverse speakers presented on HD themes and practical experiences to catalyze the thinking of participants. During all sessions, notes were taken to ensure accurate documentation. Survey results and meeting notes were analyzed by the design team and the authors of this paper-and form the basis of a policy framework document that includes: a) recommendations and best practices regarding HD for LSMPAs; b) a shared HD research agenda for LSMPAs; c) recommended steps toward a code of conduct for LSMPAs; and d) thoughts on what an HD community of practice might accomplish [47]. Given the use of a survey and the 
structure of the HD Think Tank, this intensive process represents a participatory research event that captured knowledge generated through scientific and practical experience. Furthermore, it was the first step in co-establishing the foundations of a 'community of practice' to focus on these topics. Below we report results from the HD Think Tank.

\section{Results}

The following section presents the results of the pre-meeting survey of participants and the HD Think Tank results on the importance of considering HD, best management practices, priority $\mathrm{HD}$ research topics and the community of practice.

\subsection{Survey results}

Results from the survey conducted prior to the HD Think Tank confirmed that respondents felt that HD of large-scale MPAs warrant greater emphasis in planning and implementation processes. When asked about how concerned they were about whether HD are being adequately addressed through existing management efforts and governance processes in LSMPAs, 33\% responded that they were "very concerned" and 50\% were "somewhat concerned". Similarly, $63 \%$ of survey respondents felt that HD research efforts are inadequate to support effective management in LSMPAs, whereas $16 \%$ thought research was adequate. More than $25 \%$ of respondents identified governance, cultural considerations, participatory planning processes and design gaps as priority areas of HD research for LSMPAs [Table 2].

Overall, expectations for the outcomes of the HD Think Tank were high. The highest priority outputs of included best-practices guidelines, creation of a community of practice, research agenda development, capacity-development workshops, publications and practical manuals [Table 3].

Table 2. Perceived most important knowledge gaps related to large-scale marine protected areas ( $>25 \%$ response rate).

\begin{tabular}{|l|l|}
\hline $\begin{array}{l}\text { Survey Question: What are the top three most important knowledge gaps that relate to designing and } \\
\text { managing LSMPAs? }\end{array}$ & $\begin{array}{l}\text { \% of respondents } \\
\text { selecting knowledge gap }\end{array}$ \\
\hline Priority knowledge gap & $37 \%$ \\
\hline Governance/legal/policy knowledge gaps & $34 \%$ \\
\hline Biological/ecological knowledge gaps & $34 \%$ \\
\hline $\begin{array}{l}\text { Design gaps relating to how an LSMPA is best designed to meet specific } \\
\text { management objectives or outcomes }\end{array}$ & $31 \%$ \\
\hline Traditional knowledge and traditional management system knowledge gaps & $30 \%$ \\
\hline Stakeholder engagement and participation knowledge gaps & $26 \%$ \\
\hline Cultural identity and cultural practice knowledge gaps &
\end{tabular}


Table 3. Perceived most important outputs of the think tank on the human dimensions of largescale marine protected areas ( $>25 \%$ response rate).

\begin{tabular}{|l|l|}
\hline $\begin{array}{l}\text { Survey Question: Which of the following outputs do you believe are the most important products or } \\
\text { results to be generated out of this Think Tank? }\end{array}$ & $\begin{array}{l}\text { \% of total respondents } \\
\text { selecting product/output }\end{array}$ \\
\hline Most important Think Tank product or result & $67 \%$ \\
\hline $\begin{array}{l}\text { Set of 'best practices' and recommendations on integrating HD considerations } \\
\text { into the design and management of LSMPAs }\end{array}$ & $48 \%$ \\
\hline Creation of a 'community of practice' regarding the HD of LSMPAs & $47 \%$ \\
\hline $\begin{array}{l}\text { Shared research agenda that identifies priority HD research questions or } \\
\text { projects for LSMPAs }\end{array}$ & $29 \%$ \\
\hline Series of on-site training workshops for LSMPAs relating to HD & $25 \%$ \\
\hline Summary report of the HD Think Tank session content and outputs & $25 \%$ \\
\hline $\begin{array}{l}\text { Guidebook or manual regarding how to apply and integrate HD into LSMPA } \\
\text { design and management }\end{array}$ & \\
\hline
\end{tabular}

\subsection{The importance of human dimensions}

During the first day of the HD Think Tank, participants discussed the potential impacts of ignoring or considering HD in LSMPAs. Participants identified a number of positive consequences that could occur as a result of correctly integrating and applying HD in the design and management of existing and future LSMPAs. In-depth consultations, community engagement, and participation, both prior to and during LSMPA establishment, could lead to more support for LSMPA creation, help to secure political will and buy-in of elected officials and leaders, and improve design. Considering economic, cultural, and food security issues might help to identify how to offset lost fishing income, ensure that traditional knowledge systems and customary management practices are incorporated into management, and identify ways to ensure that resources are available to feed future generations. Explicitly recognizing cultural considerations can help to rejuvenate cultural values and practices and increase pride in place. Improved stakeholder integration into LSMPA management will enable successful adaptive management through time and increase compliance with marine resource rules and regulations. Together, these considerations can facilitate the continuation, persistence, and effectiveness of LSMPAs over time. Participants felt that top-down declaration and ignoring the HD of LSMPAs might produce such issues as alienation, loss of trust, enforcement and compliance issues, lack of political will, disagreements and conflict and human rights issues. The presence of these types of HD issues, participants believed, could ultimately undermine legitimacy, support and the ecological effectiveness of LSMPAs.

\subsection{Best management practices}

During the second day of the HD Think Tank, a series of knowledge cafés were held to generate best practices under eight themes determined by the meeting design team. The eight themes were: 1 ) integration of culture and traditions, 2) effective public and stakeholder engagement, 3) maintenance of livelihoods and wellbeing, 4) promotion of economic sustainability, 5) conflict management and resolution, 6) institutional transparency and (mis)matching ideas and institutions, 7) legitimate and appropriate governance, and 8) social justice and empowerment. These themes were developed based on insights developed from initial brainstorming sessions 
on HD of LSMPAs during the first day of the HD Think Tank and were intended to cover the main areas of HD. However, they were not meant to be exhaustive and some overlap among themes was unavoidable. Each participant had the opportunity to engage in two knowledge cafés, each of which had about 45 minutes of discussion time. Participants were allowed to choose, and some themes had more participants than others. The knowledge cafés consisted of facilitated discussions, during which participants wrote their ideas of best practices on "sticky notes" that were displayed on a flip chart. These results were then collated in a draft of best practices (See [47]) and shared for feedback before and during the World Conservation Congress in Honolulu in September 2016.

Table 4 summarizes the key concepts offered by participants out of the knowledge cafés for each of the eight themes. (A longer and less edited version of the ideas emerging from the discussion of best practices is included in Supplemental Materials-Appendix C.) Since LSMPAs occur in vastly different social, economic, political and cultural contexts, their implementation and management involves a wide range of stakeholder groups and best practices will be more or less applicable depending on context. Thus these best practices are considerations, rather than a comprehensive list that must be applied. 
Table 4. A summary of the key concepts offered on eight themes of best management practices for integrating human dimensions into large-scale marine protected areas. (A more complete record of ideas can be found in Appendix B).

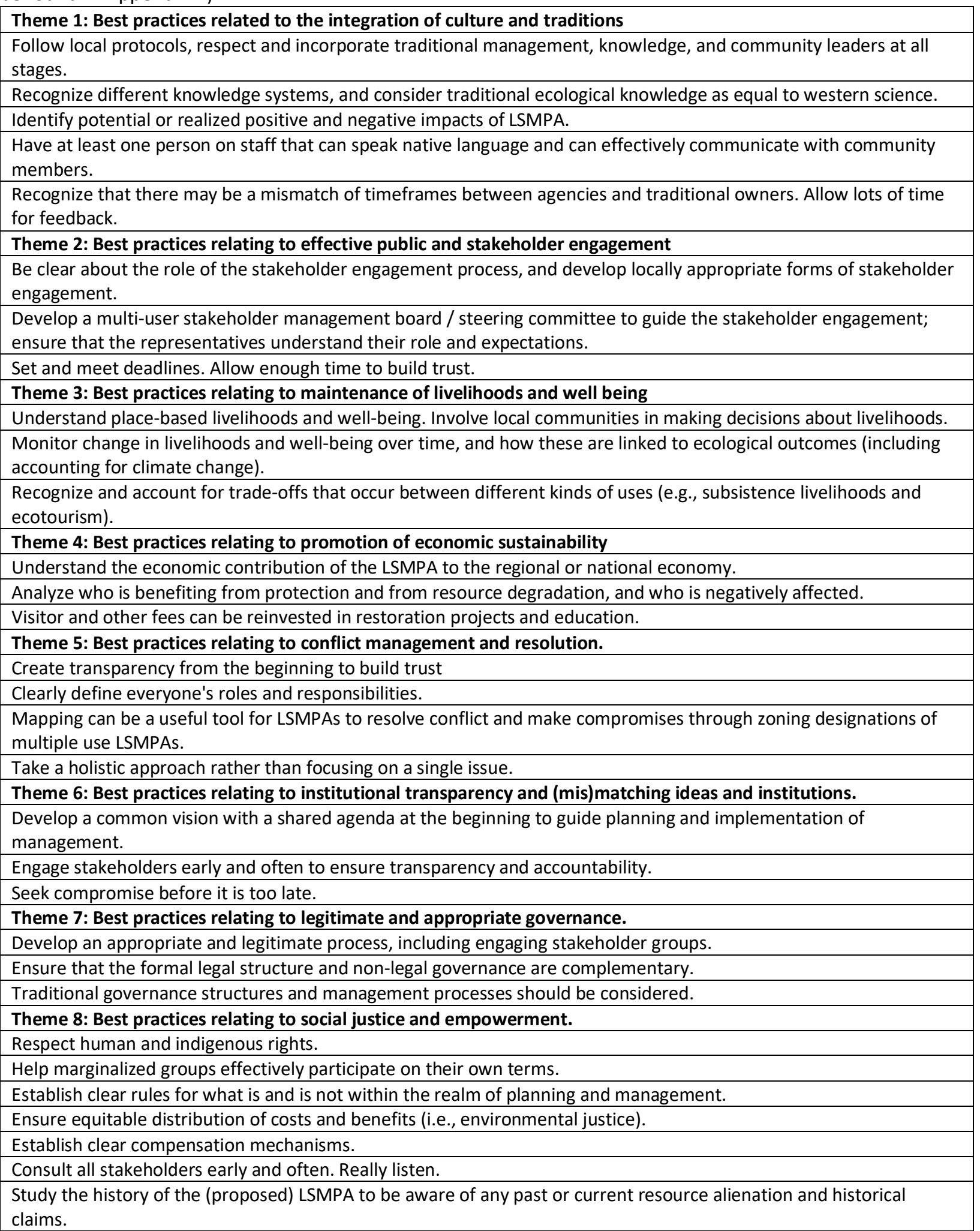




\subsubsection{Integration of culture and traditions}

A cornerstone best management practice for incorporating HD within LSMPA design and management is the appropriate integration and support (including promotion) of local and indigenous cultural norms, values, knowledge, and traditions within LSMPA design and implementation. Such efforts should appropriately and respectfully incorporate and validate traditional knowledge systems and customary management practices.

\subsubsection{Effective public and stakeholder engagement}

Another cornerstone best management practice is effectively engaging the general public and key stakeholder groups within the design and management of LSMPAs. Ideally, such engagement should be conducted with the intention of providing meaningful, regular, and focused opportunities for representatives of the public and key stakeholder groups to actively and directly participate in LSMPA decision-making structures and deliberate on management actions to be taken.

\subsubsection{Maintenance of livelihoods and well being}

Ideally, LSMPAs should be designed and implemented in such a way that they inherently link to maintaining and even strengthening the livelihoods and human well being for residents living in and around the LSMPA. In the case of remote LSMPA sites, such livelihood and well being connections may appear to be distant or unrelated; however, such remote LSMPAs should work to understand and 'connect' the importance and existence value of the LSMPA to the daily lives and social well-being of stakeholders and the public.

\subsubsection{Promotion of economic sustainability}

LSMPAs can have positive and negative economic consequences, which should be understood. Compensation (monetary or otherwise) should be provided to those negatively affected. Economic valuation can be used to highlight the multi-faceted values of LSMPAs, and user fees or conservation trusts can be used to re-invest in conservation projects and local communities.

\subsubsection{Conflict management and resolution}

Conflict may arise in LSMPAs because of the multiple perspectives, values and trade-offs inherent with resource management. Resolving conflicts involves being proactive, creating a transparent process, and building trust. Ways of resolving conflicts may be context-specific.

\subsubsection{Institutional transparency and (mis)matching ideas and institutions}

To avoid mismatching agendas and institutions between key implementing actors and stakeholders of LSMPAs, a transparent (i.e., clear, open, and easily-accessible) management decision-making process should be shared actively and regularly with affected stakeholder groups and the public. The decision-making process should be justified and consistent with the actual institutional mandates (legislative, regulatory) of the relevant/designated management authorities (designated agencies and management bodies) for the LSMPA. 


\subsubsection{Legitimate and appropriate governance}

LSMPAs should be designed and managed under a governance framework that respects the laws, traditions, norms, priorities and sovereignty of the home nation. A solid understanding and application of HD considerations will ensure that governance is legitimate and appropriate to each LSMPA context, thereby building trust, buy-in, respect, and support for site management and perpetuation.

\subsubsection{Social justice and empowerment}

A documented concern with LSMPAs is that their designation and management is associated with social injustice and disempowerment or disenfranchisement of key stakeholder groups by the management authority and/or supporting site partners/advocates. Related concerns include the role of LSMPAs as an instrument for eminent domain or 'ocean grabbing' by central management authorities, thereby displacing, diminishing, or eliminating indigenous community rights with a traditional and/or legal claims to the waters under declaration. On the other hand, LSMPAs might be conceived of as a tool that can be used to promote and validate indigenous rights and legal claims to traditional management or customary marine tenure or as a means to promote "whole domain management" through integrating top-down and bottom-up considerations into the design and management of an island nation's Exclusive Economic Zone. In order to ensure that such social justice issues are clearly and fully understood, site managers and management authorities must be committed to recognizing, understanding, and integrating the local/site context in terms of political, historical, and cultural contexts.

\subsection{Areas of future HD research identified}

Another goal of the HD Think Tank was to develop a research agenda related to the HD of LSMPAs, through facilitated small group discussions. More specifically, the goal was to create and advance a shared (co-produced) research agenda by collaboratively engaging the broader community of practice, HD researchers, proponents and critics of LSMPAs in identifying key knowledge gaps and research priorities. Ultimately, the objective is to develop, implement, and continually update a shared research agenda that supports effective and socially just conservation through LSMPAs. Although different sites and institutions will have different research priorities, this shared research agenda can serve as a resource to guide the collective efforts of researchers, LSMPA site managers, NGOs, policy-makers and resource users - as well as donors wishing to fund research that will improve the management of LSMPAs.

While organizing the HD Think Tank, two of this paper's authors published a paper (with others) that called for a distinct social science research agenda on LMPAs reflective of their unique features and the needs of diverse actors and interests [10]. Drawing on interviews, participant observation at the 2014 World Parks Congress, a literature review, and the authors' research experiences, Gruby et al. [10] identified the following four priority research themes: scoping HD, governance, politics, and social and economic outcomes. The HD Think Tank took this a step further through co-developing with the participants a more comprehensive and shared social science research agenda for LMPAs that identified not only broad research categories but also specific knowledge gaps and priority research projects within them. Table 5 outlines these 
gaps and priorities, classifying them according to thematic categories of research proposed by Gruby et al. [10], with the addition of a distinct category for 'culture and tradition'. The authors did not use predefined research themes to frame our discussions at the HD Think Tank in an effort to remain open to the emergence of new or different priority research themes.

In addition to identifying knowledge gaps and research priorities, HD Think Tank participants felt it was important to discuss HD research protocols to identify research best practices and research ethics standards. First, these discussions highlighted the need for research that is transparent, inclusive, collaborative, and respectful of indigenous rights, values, and knowledge. Research regarding the HD of LSMPAs should include stakeholder participation in project design and implementation. The need for researchers to commit to returning and communicating results was also emphasized. Second, the authors recognized the value of diverse social science disciplines, methodologies, and approaches for implementing the research agenda. However, research must also be tailored to suit the question, context, capacity, expertise, time, and resources available. Finally, the attendees at the HD Think Tank felt that a social code of conduct for marine conservation is worth pursuing and that a first step in this process would be a scoping study of pre-existing codes of conduct and related policy documents.

\subsection{Roles for the community of practice}

During the HD Think Tank, there was also a productive discussion about the potential roles that an LSMPA HD community of practice might fulfill. The roles discussed included: a) Coordinating and facilitating collaborative social science research relating to HD of LSMPAs; b) Promoting awareness and sharing knowledge regarding the HD of LSMPAs; c) Conducting outreach across multiple disciplines and key target audiences; d) Learning from and integrating relevant indigenous cultural perspectives and values within the design and management of LSMPAs; e) Researching, developing, and documenting "Guiding Principles" and best management practices of HD in LSMPAs; f) Building a "code of conduct" for LSMPAs that is upheld by the international conservation community; g) Engaging donors meaningfully and recruit their support on incorporating HD at LSMPAs; h) Building on Big Ocean, serve as peer-to-peer learning network to facilitate knowledge transfer and building capacity; i) Recruiting commercial/industry participation and representation; j) Elevating LSMPAs and promote successful LSMPA design and management; and k) Giving member sites a voice. These tasks would be accomplished through upholding a set of core values such as collaboration, objectivity, engagement, non-exclusivity, transparency and equity. The exact format and governance structure that such a community of practice might take is a topic that was discussed preliminarily but that deserves further elaboration (See [47] for additional details). 
Table 5. Knowledge Gaps and Research Priorities Identified by the Community of Practice ${ }^{a}$.

\begin{tabular}{|c|c|}
\hline Knowledge Gaps & Priority Research Projects \\
\hline $\begin{array}{l}\text { Scoping Human Dimensions } \\
\text { - What are clear terms and definitions that can be used } \\
\text { relating to the HD of LSMPAs? }\end{array}$ & $\begin{array}{l}\text { - Conduct a rapid desk study using secondary data review } \\
\text { and online self-administered questionnaire with LSMPA } \\
\text { managers and partners to clarify HD terminology across } \\
\text { LSMPA sites. Use results from rapid study to develop a } \\
\text { shared lexicon that can be circulated within the LSMPA HD } \\
\text { community of practice for review and comment. }\end{array}$ \\
\hline $\begin{array}{l}\text { Governance } \\
\text { - What is the level of community/public engagement and } \\
\text { empowerment at new/established LSMPAs? }\end{array}$ & $\begin{array}{l}\text { - Assess the relative level of community and stakeholder } \\
\text { participation in the design and management of LSMPAs } \\
\text { across willing sites; assess the relative social effectiveness of } \\
\text { participatory processes through stakeholder analysis and } \\
\text { network analysis. Key dimensions to investigate include how } \\
\text { 'scalable' public participation approaches are, and how to } \\
\text { avoid expert domination of the public/stakeholder } \\
\text { engagement process }\end{array}$ \\
\hline $\begin{array}{l}\text { - What is the influence of differing LSMPA governance } \\
\text { frameworks on public/ stakeholder engagement and } \\
\text { perception of LSMPAs? What is the relative effectiveness of } \\
\text { different LSMPA governance approaches?* }\end{array}$ & $\begin{array}{l}\text { - Conduct perception and attitudinal studies (via multiple } \\
\text { interview techniques) to document the perceived degree of } \\
\text { equity, transparency, and legitimacy of LSMPA-related } \\
\text { decisions made, and how these correlate with the perceived } \\
\text { level of LSMPA site 'success' and impacts (good and bad). }\end{array}$ \\
\hline $\begin{array}{l}\text { Politics } \\
\text { - What are the motives and agendas of NGO partners and } \\
\text { stakeholders in supporting LSMPA designation and } \\
\text { management? }\end{array}$ & $\begin{array}{l}\text { - Complete a political-economic assessment inclusive of } \\
\text { stakeholder analysis at specified LSMPAs to identify socio- } \\
\text { political and socio-economic lessons and needs associated } \\
\text { with LSMPA design and management. }\end{array}$ \\
\hline $\begin{array}{l}\text { Socio-Economic } \\
\text { - How can a wide range of human uses and interests } \\
\text { (economic, cultural, etc.) be best incorporated within LSMPA } \\
\text { design and management planning?* }\end{array}$ & $\begin{array}{l}\text { - Complete the mapping and comparison of current human } \\
\text { uses across multiple LSMPAs; as part of this, conduct } \\
\text { spatially driven cost-benefit analyses of various human uses } \\
\text { inside and outside the LSMPAs. Include economic, intrinsic, } \\
\text { and spiritual valuations of the costs and benefits. }\end{array}$ \\
\hline $\begin{array}{l}\text { - What are the ecosystem services of LSMPAs and who are } \\
\text { the beneficiaries and cost-bearers? }\end{array}$ & $\begin{array}{l}\text { - Conduct cost/benefit analyses of ecosystem services from } \\
\text { LSMPA sites that are to be provided to the assumed and/or } \\
\text { identified 'beneficiaries' of each LSMPA. }\end{array}$ \\
\hline $\begin{array}{l}\text { - What are the relative costs and benefits of LSMPAs } \\
\text { compared to other marine management tools? }\end{array}$ & $\begin{array}{l}\text { - Complete a comparative analysis of the policies, } \\
\text { processes, outputs, and impacts of LSMPAs versus other } \\
\text { coastal and marine resource management tools. }\end{array}$ \\
\hline $\begin{array}{l}\text { - What is the perceived level of impact (positive and/or } \\
\text { negative) of LSMPAs on stakeholders, including stakeholder } \\
\text { connection to the site? }\end{array}$ & $\begin{array}{l}\text { - Conduct socioeconomic and stakeholder analysis across } \\
\text { LSMPAs to document actual and potential social impacts } \\
\text { (both positive and negative impacts) of LSMPAs on } \\
\text { stakeholders. }\end{array}$ \\
\hline $\begin{array}{l}\text { - What is the socioeconomic value of living and cultural } \\
\text { resources within LSMPAs? }\end{array}$ & $\begin{array}{l}\text { - Complete a comparative socioeconomic analysis relating } \\
\text { to the living and non-living (with a focus on cultural) } \\
\text { resources found across LSMPA sites. }\end{array}$ \\
\hline $\begin{array}{l}\text { - How can LSMPAs be classified in relation to different HD } \\
\text { aspects and issues? }\end{array}$ & $\begin{array}{l}\text { - Complete a social characterization of existing LSMPAs in } \\
\text { relation to various HD- related aspects and elements (e.g., } \\
\text { demographics, economic conditions, resource use behaviors, } \\
\text { etc.). Comparative results out of the characterization could } \\
\text { include site categorization. Could be initially completed as a } \\
\text { remote desk study with participating LSMPAs. }\end{array}$ \\
\hline $\begin{array}{l}\text { Culture and Tradition } \\
\text { - How can cultural practices/values and traditional } \\
\text { knowledge be best incorporated into LSMPA design and } \\
\text { management?* }\end{array}$ & $\begin{array}{l}\text { - Complete a comparative case study analysis on the } \\
\text { integration of cultural traditions and practices within } \\
\text { LSMPA design and management at existing and proposed } \\
\text { sites. This would include analysis of values and connections } \\
\text { to site/place, particularly within indigenous communities. }\end{array}$ \\
\hline $\begin{array}{l}\text { - What is the level of equity in values, particularly cultural } \\
\text { and intrinsic values? What is the level of understanding of } \\
\text { stakeholder values? }\end{array}$ & $\begin{array}{l}\text { - Conduct a values assessment over the cultural uses and } \\
\text { values of residents and indigenous peoples in and around } \\
\text { existing LSMPAs. Use joint problem identification to } \\
\text { compare and contrast cultural values. }\end{array}$ \\
\hline
\end{tabular}


${ }^{\text {a }}$ Research projects were brainstormed based upon identified knowledge gaps, so they are presented together. However, they do not align in all cases because participants were free to brainstorm research projects however they liked. Items marked with "*" were deemed highest priority by HD Think Tank participants.

\section{Discussion}

As these results demonstrate, through drawing on the collective experience and knowledge of the more than 125 participants at the HD Think Tank significant advancements were made in our knowledge of the HD of LSMPAs. Below, the authors discuss future directions in researching and incorporating HD into LSMPAs design and management, reflect on this global effort to coproduce knowledge and re-orient practice on the HD of LSMPAs, and invite others to join a nascent community of practice on the HD of large-scale marine conservation.

\subsection{Integrating human dimensions into LSMPAs}

The consequences of global environmental change and marine degradation for economies, societies, and cultures in the 21st century will be profound. Logically, conservation efforts have expanded in scope and ambition. This will inevitably be challenging, controversial and have social impacts $[6,25]$. Balancing the potential positives of largescale marine conservation with the consideration of HD issues in the design and management of LSMPAs was a key impetus for the HD Think Tank. Past recommendations for designing and managing MPAs have primarily been developed with reference to smaller coastal MPAs [36,48-56]. However, over recent years there has been increasing attention to how to design and manage LSMPAs [33,57]including how to incorporate HD considerations [10,57]. In particular, attention has been paid to the integration of cultural considerations [31], the challenges of enforcement $[23,58]$, creation of effective and adaptive management $[12,59,60]$, the establishment of effective governance regimes $[32,61,62]$, the merging of top-down and bottom up processes during the design phase $[63,64]$ and the management of social impacts [26].

The authors acknowledge that many of the best practices emerged from the collective research and experience-based understanding of management for smaller, coastal MPAs. One challenge that became apparent throughout the HD Think Tank was ensuring that attendees were focusing on ideas specific to the design and management of largescale MPAs versus smaller MPAs. This is evident in the fact that many of the best management practices identified are not LSMPA specific and the "how" of applying them to LSMPAs is not explained. Thus, these results could be critiqued as falling short of key insights into large-scale marine conservation. While many lessons from small MPAs are broadly applicable, the effective design, governance, and management of LSMPAs is likely highly context-specific and necessarily must consider the specific institutions, laws, cultures, histories, and socio-economic situations of different places. Rather than perceiving this outcome as a shortcoming, it can be perceived as a limitation of current understanding and rationale for increased research into the HD of LSMPAs and the sharing of lessons through a community of practice. Thus, moving forward, the best practices should be seen as a living document that will be expanded and improved upon by researchers and practitioners in the LSMPA HD community of practice. 


\subsection{Research on HD of LSMPAs}

Prior to the HD Think Tank, Gruby et al. [10] and Christie et al. [65] had proposed guiding questions for an analysis of the HD of LSMPAs. There was substantial overlap in content with the questions identified by HD Think Tank participants, illustrating that academics and practitioners share many concerns and interests. However, Gruby et al. and Christie et al. also identified some questions that were not raised or deeply explored by HD Think Tank participants, including questions related to: 1 ) conceptualizations of human-environment relations; 2) technologies of visualization, surveillance, and enforcement; 3 ) governance interactions between LSMPAs and other local, national, and international policies and conservation measures; 4) power relations among actors involved in LSMPAs; 5) protocols for conducting research and conservation, especially with indigenous communities. In some cases, these questions were addressed in other ways. For example, while HD Think Tank participants did not identify a question related to research protocols, they did discuss the need for appropriate conduct when doing research and even identified the need for a code of conduct (for all actors engaged in conservation research, advocacy, and management activities). And although topics related to power were not the explicit foci of research questions, HD Think Tank participants discussed issues related to power throughout the process, including concerns about whose interests are represented in LSMPA advocacy and planning processes, how management decisions are made and even when LSMPAs might constitute 'ocean grabbing'. Another difference between the academic guiding questions and the output of the HD Think Tank reflects two ongoing tensions related to conservation social science: 1) whether research should be theoretical or applied and 2) whether research should be 'on' conservation (to develop understanding about how it occurs) versus 'for' conservation (to produce research in its support) $[35,66,67]$. The authors contend that research related to the HD of LSMPAs should be relevant for managers, local communities, and other constituencies, but do not presume that this necessarily equates with applied research 'for' conservation. Indeed, research 'on' the HD of LSMPAs may produce insights that are either positive and innovative or challenging and disruptive to the status quo [35]. Both critical and constructive research insights can be instructive when seeking to improve the way that LSMPAs are designed and managed. Finally, the authors learned that it is challenging to co-produce research questions and research projects that will be academically rigorous/theoretically rich and applicable to real-world management situations-especially in the context of a short workshop. This may have been due partly to participants' lack of training in and experience with social science research and methods. While challenging, co-design of research is necessary and productive.

\subsection{Reflections on the think tank}

The HD Think Tank was a unique gathering that came at a strategic time and seems to have inspired many who attended to re-examine challenging issues and commit to an ongoing collaboration. As discussed in the introduction, our goal was to develop a facilitated and participatory process that aligned with the ideals of action research and knowledge coproduction $[42,43]$. The authors strived to co-design the process, co-produce the ideas and outputs and co-implement the recommendations and actions through developing a community of practice. The HD Think Tank was not intended to be a 'one-off' meeting, rather it was 
intended to be a collaborative and action-oriented process that will result in novel and engaging research, improved conservation policies and practice that takes into account HD, and continued mutual learning amongst a diverse constituency of scholars, conservation practitioners, policy makers, community leaders, and others [Fig. 2]. Here, to promote transparency and learning, the authors reflect honestly on whether our efforts achieved these goals.

First, the authors reflect on the collaborative design process. While members of the 'HD Think Tank design team' were from diverse backgrounds and members of institutions with diverse institutional commitments and cultures, the common belief in the importance of these ideas, a shared vision and strong desire to host this event created a remarkable degree of passion and commitment to the HD Think Tank. Yet, each individual and institution had slightly differing goals in this process that ultimately created a stronger process and HD Think Tank. The scholarly interests of HD academics complemented the practical interests of LSMPA managers and marine conservationists. Both perspectives were necessary, and mutual respect allowed for sharing of responsibilities and balanced, multi-objective planning but not without a healthy level of debate during the design process.

Second, the HD Think Tank itself had a number of strengths and a few weaknesses in the way that it was designed. Strengths included the high degree of participation in the meeting, the skilled facilitation, the applied focus, the diverse set of actors who attended and brought a combination of academic and practical knowledge. In particular, it is important to highlight the positive contribution of inviting and funding the attendance of such a diverse group of representatives from both the Global North and Global South and from different organizations and interest groups (e.g., HD scholars, NGO conservationists, LSMPA site managers, Pacific Island cultural leaders, industry and donors). Having both LSMPA advocates and critics present at the workshop led to productive, and occasionally spirited, discussions. Careful attention to meeting design and active facilitation helped create space for contradictory perspectives to be presented and debated; however, we may not have been successful in ensuring that all opinions were voiced. In agreement with principles described in Turner et al. [41], the HD Think Tank design and meeting outcomes represent an example of knowledge co-production whereby people from diverse backgrounds and perspectives created knowledge and commitments in common. Overall, engaging in this type of co-production process produced an initiative, insights, and outputs that have a high level of legitimacy and cannot be easily dismissed. Yet, there were a few weaknesses that could be improved upon in future initiatives. First, representatives from North America were overrepresented, as were academics, NGOs and managers, while other geographies and stakeholder groups were under represented (Appendix A). This means that results may not be representative of the diversity of perspectives. Second, the process used during the HD Think Tank to identify categories of best practices for management was not as structured as it could have been. Following a more rigorous and structured decision-making process during this stage of the meeting may have produced a more complete list of best practices. 
According to the pre-HD Think Tank survey, respondents reported a strong interest in an ongoing collaboration. Based on the results of an exit survey that was completed by 49 of the 125 HD Think Tank participants (39\% response rate), the majority of respondents agreed that a HD community of practice for LSMPAs was developed and launched, and that this community should build upon the meeting outputs to identify and further develop best management practices within the eight themes [see Table 1]. A common point of feedback offered within exit survey results was the value of the wide diversity of participants and useful mix of varying perspectives and suggestions that such a diverse community of practice brings to respectfully, but critically, consider how best to manage LSMPAs and integrate HD. At the end of the meeting during a plenary session, 20 organizations and individuals announced their willingness to technically, financially, and/or logistically support the implementation of a community of practice focusing on the HD of LSMPAs. These announcements included offers from LSMPA site managers, academic institutions, government agencies, non-governmental groups, and donors.

Has the HD Think Tank led to action? The authors and others have organized follow-up activities to facilitate feedback, disseminate the findings, and foster adoption of results. The results of the workshop were collated in "A Practical Framework for Addressing the HD of Large-Scale Marine Protected Areas" [47]. A workshop at the IUCN World Conservation Congress in Honolulu in September 2016 allowed for the presentation and further discussion of HD Think Tank outcomes. Several members of the design team and broader Community of Practice also organized a meeting at the World Conservation Congress that has led to an appeal for a marine conservation code of conduct which is relevant beyond just large-scale marine conservation [68]. Several of the authors of this paper are currently undertaking additional research on the HD of LSMPAs. A theme issue for a peer reviewed journal on the HD of LSMPAs is currently in press [69]. The authors are hopeful that this initiative will convince proponents and managers to consider and take actions to incorporate HD aspects in all stages of conservation planning and management to improve the probability of social and ecological success in LSMPAs. Through personal communications, it is clear that several of the managers present at the HDTT are applying the best practices in their sites. But, ultimately, only time will tell whether this initiative will lead to concrete actions more broadly to integrate HD into LSMPAs.

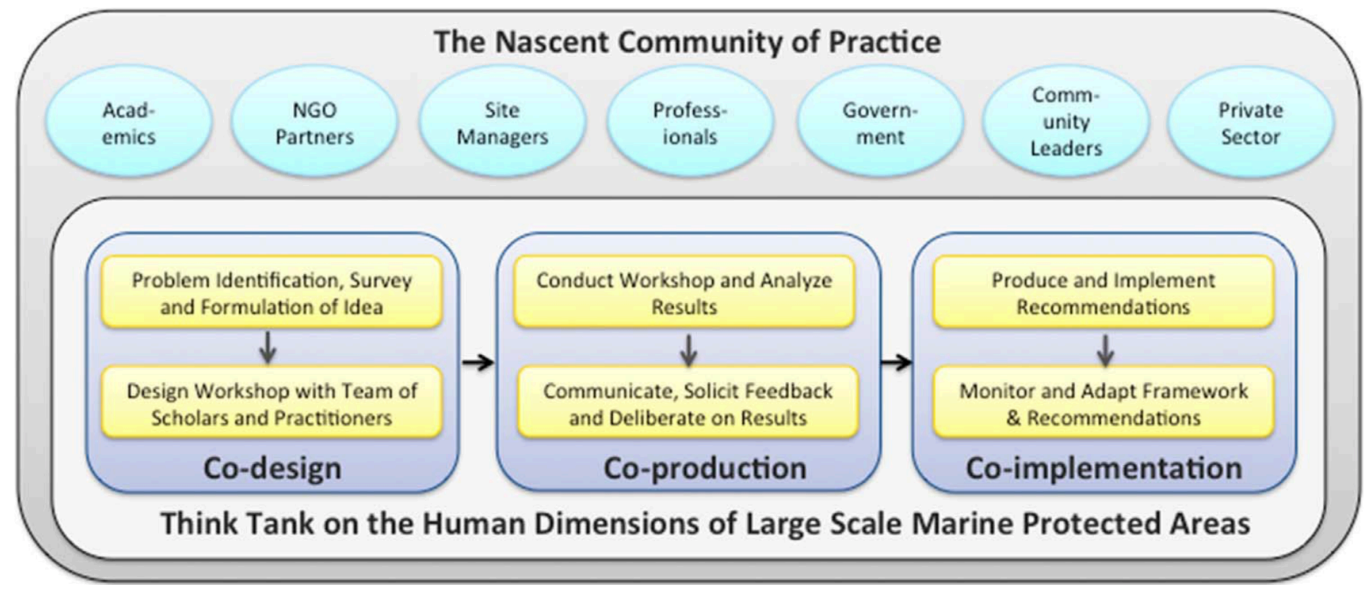

Fig. 2. Visual representation of the Think Tank on the Human Dimensions of Large Scale Marine Protected Areas as a global knowledge co-production exercise and nascent community of practice (adapted from [34]). 


\subsection{Toward a community of practice}

This nascent Community of Practice brings together a diverse set of actors who share an interest in the HD of LSMPAs. Such communities of practice have begun to emerge in other realms such as forestry and livelihoods [70]. The collaboration between academics, conservation practitioners and an existing learning network (Big Ocean) is potentially a powerful partnership. The academics bring theory and research-derived insights. The practitioners bring field experience. The Big Ocean learning network allows for the rapid diffusion of insights and the means to implement best HD practices. The diversity of perspectives and the coupling of academic research with practical insights results in a useful creative tension within the Community of Practice that will provide more credibility to any recommendations coming from the Community of Practice.

Yet, there remains a significant number of governance and practical considerations and questions related to creating a Community of Practice. The funding to foster and expand this collaboration has not been secured and it is likely that the coordination of the Community of Practice will continue to evolve. What format should it take? What should be its institutional home? What will be the main objectives and functions of the network? How should decisions be made and by whom? Who should be involved in decision-making and in the broader network? Where will the funding come from? Who will carry out administrative tasks? Where will communication come from? Who should own the products? Through striving to create a community of practice, the authors are trying to create a model that fulfills a different role than either research institution or conservation organization. But, in doing so, this effort is charting somewhat unfamiliar territory. Given that institutional cultures and incentives vary within academic, government, NGO institutions, the leadership for the Community of Practice will need to be representative, the membership and decision-making processes will need to be inclusive, and goals will need to be diverse and complementary. Continuing to have discussions about the questions raised above is important.

\section{Conclusion}

The central goal of this particular HD Think Tank and the nascent Community of Practice is to improve the effectiveness of LSMPA implementation through the increased understanding and incorporation of human dimension considerations in LSMPA design, implementation, and evaluation. This goal and the associated activities, including the development of best practices, a HD research agenda, and future research collaborations, are ambitious and closely related to trends in conservation science, marine conservation, and fisheries management. While the goals and outputs were most explicitly linked to LSMPAs, which do have unique HDs [69,71], the authors suggest that the norms of practice emerging from the Think Tank apply broadly to diverse types of ocean governance processes at various scales. Best practices such as transparent, participatory, and culturally-appropriate management are not only relevant to LSMPAs.

Furthermore, increasing our understanding and building management capacity and increasing our understanding of the science of LSMPAs is essential in the short-term. However, to ensure long-term success of the field more broadly, the next generation should be mentored to 
address global trends and threats, and to understand the multidisciplinary nature of sound, sustainable ocean governance-including sustaining relationships with community, addressing human rights issues, food security, and perpetuation of culture and livelihoods. Finally, in the spirit of an ongoing and inclusive process, the authors welcome and invite the interest and participation of other individuals or organizations to partner with us in moving this initiative forward. Ultimately, addressing complex and broad HD challenges will require a diverse and committed community of practice.

\section{Acknowledgements}

This paper and the Think Tank on HD of LSMPAs were made possible by the generous support of the Pew Charitable Trusts (contract ID 29018), the United States National Oceanographic and Atmospheric Administration (NOAA), the Social Sciences and Humanities Research Council (SSHRC) of Canada, the Pristine Seas Program of the National Geographic Society, and Conservation International. The Think Tank would not have been possible without the support of the following organizing committee members: the University of Washington (PC, LG, NJB); NOAA's Office of National Marine Sanctuaries (AW); Big Ocean (NL); the University of British Columbia (NJB); the University of Victoria (NCB); Colorado State University (RLG); the University of Guelph (NJG); James Cook University (JD), Conservation International (ST), and the University of Hawai'i (AF). NJB acknowledges the support of the Liber Ero Fellowship Program. NJG and RLG acknowledge the support of the Oak Foundation (grant \#: ORIO-14-045). By participating in the Think Tank, 125 professionals from around the world contributed content and insight into this paper (Appendix A). The authors acknowledge and deeply appreciate their contributions and engagement as collaborators and co-producers of this knowledge. It is our hope that the content and ideas outlined in this paper faithfully represents their original contributions and perspectives. The authors look forward to more dialogue and improvement of conservation practice based on an improved understanding of how society interacts with the ocean and with marine conservation efforts. PC acknowledges the support of the Pew Charitable Trusts (contract ID 29018).

\section{Appendix A. Supporting information}

Supplementary data associated with this article can be found in the online version at http://dx.doi.org/10.1016/j.marpol.2017.08.002.

\section{References}

[1] N. Gray, Sea change: exploring the international effort to promote marine protected areas, Conserv. Soc. 8 (2010) 331, http://dx.doi.org/10.4103/0972-4923.78149.

[2] L.J. Wood, L. Fish, J. Laughren, D. Pauly, Assessing progress towards global marine protection targets: shortfalls in information and action, Oryx 42 (2008) 340-351, http://dx.doi.org/10.1017/S003060530800046X. 
[3] E.M. De Santo, Missing marine protected area (MPA) targets: how the push for quantity over quality undermines sustainability and social justice, J. Environ. Manag. 124 (2013) 137146, http://dx.doi.org/10.1016/j.jenvman.2013.01.033.

[4] T. Agardy, P. Bridgewater, M.P. Crosby, J. Day, P.K. Dayton, R. Kenchington, D. Laffoley, P. McConney, P.A. Murray, J.E. Parks, L. Peau, Dangerous targets? Unresolved issues and ideological clashes around marine protected areas, Aquat. Conserv. Mar. Freshw. Ecosyst. 13 (2003) 353-367, http://dx.doi.org/10.1002/aqc.583.

[5] T. Agardy, J. Claudet, J.C. Day, "Dangerous Targets" revisited: old dangers in new contexts plague marine protected areas, Aquat. Conserv. Mar. Freshw. Ecosyst. 26 (2016) 7-23, http://dx.doi.org/10.1002/aqc.2675.

[6] P.J.S. Jones, E.M. De Santo, Viewpoint - Is the race for remote, very large marine protected areas (VLMPAs) taking us down the wrong track? Mar. Policy 73 (2016) 231-234, http://dx.doi.org/10.1016/j.marpol.2016.08.015.

[7] R. Devillers, R.L. Pressey, A. Grech, J.N. Kittinger, G.J. Edgar, T. Ward, R. Watson, Reinventing residual reserves in the sea: are we favouring ease of establishment over need for protection? Aquat. Conserv. Mar. Freshw. Ecosyst. 25 (2015) 480-504, http://dx.doi.org/10.1002/aqc.2445.

[8] R.J. Toonen, T. Aulani Wilhelm, S.M. Maxwell, D. Wagner, B.W. Bowen, C.R.C. Sheppard, S.M. Taei, T. Teroroko, R. Moffitt, C.F. Gaymer, L. Morgan, N. Lewis, A.L.S. Sheppard, J. Parks, A.M. Friedlander, One size does not fit all: the emerging frontier in large-scale marine conservation, Mar. Pollut. Bull. 77 (2013) 7-10, http://dx.doi.org/10.1016/j.marpolbul.2013.10.039.

[9] L. Boonzaier, D. Pauly, Marine protection targets: an updated assessment of global progress, Oryx 50 (2016) 27-35, http://dx.doi.org/10.1017/S0030605315000848.

[10] R.L. Gruby, N.J. Gray, L.M. Campbell, L. Acton, Toward a social science research agenda for large marine protected areas: social science and large MPAs, Conserv. Lett. 9 (2016) 153-163, http://dx.doi.org/10.1111/conl.12194.

[11] M.D. Spalding, I. Meliane, A. Milam, C. Fitzgerald, L.Z. Hale, Protecting marine spaces: global targets and changing approaches, Ocean Yearb. Online 27 (2013) 213-248, http://dx.doi.org/10.1163/22116001-90000160.

[12] J.C. Day, Zoning-lessons from the Great Barrie Reef Marine Park, Ocean Coast. Manag. 45 (2002) 139-156, http://dx.doi.org/10.1016/S0964-5691(02)00052-2.

[13] M. Osmond, S. Airame, M. Caldwell, J. Day, Lessons for marine conservation planning: a comparison of three marine protected area planning processes, Ocean Coast. Manag. 53 (2010) 41-51, http://dx.doi.org/10.1016/i.ocecoaman.2010.01.002. 
[14] J.C. Day, The Great Barrier Reef Marine Park - the grandfather of modern MPAs, in: G. Wescott, J. Fitzsimons (Eds.), Big Bold Blue Lessons Aust. Mar. Prot. Areas, Csiro

Publishing, Australia, 2016.

[15] C. Pala, Scientists laud Bush's blue legacy but want more, Science 323 (2009) 192-193, http://dx.doi.org/10.1126/science.323.5911.192.

[16] S.E. Lester, B.S. Halpern, L. Grorud-Coveret, J. Lubchenco, B.I. Ruttenberg, S.D. Gaines, S. Airame, S.S. Warner, Biological effects within no-take marine reserves: a global synthesis, Mar. Ecol. Prog. Ser. 384 (2009) 33-49.

[17] B.S. Halpern, S.E. Lester, J.B. Kellner, Spillover from marine reserves and the replenishment of fished stocks, Environ. Conserv. 36 (2009) 268-276, http://dx.doi.org/10.1017/S0376892910000032.

[18] E.T. Game, H.S. Grantham, A.J. Hobday, R.L. Pressey, A.T. Lombard, L.E. Beckley, K. Gjerde, R. Bustamante, H.P. Possingham, A.J. Richardson, Pelagic protected areas: the missing dimension in ocean conservation, Trends Ecol. Evol. 24 (2009) 360-369, http://dx.doi.org/10.1016/j.tree.2009.01.011.

[19] L. Wedding, M. Yoklavich, Habitat-based predictive mapping of rockfish density and biomass off the central California coast, Mar. Ecol. Prog. Ser. 540 (2015) 235-250, http://dx.doi.org/10.3354/meps11442.

[20] N.A.J. Graham, T.R. McClanahan, The last call for marine wilderness? BioScience 63 (2013) 397-402, http://dx.doi.org/10.1525/bio.2013.63.5.13.

[21] A. Balmford, P. Gravestock, N. Hockley, C.J. McClean, C.M. Roberts, The worldwide costs of marine protected areas, Proc. Natl. Acad. Sci. USA 101 (2004) 9694-9697, http://dx.doi.org/10.1073/pnas.0403239101.

[22] G.J. Edgar, R.D. Stuart-Smith, T.J. Willis, S. Kininmonth, S.C. Baker, S. Banks, N.S. Barrett, M.A. Becerro, A.T.F. Bernard, J. Berkhout, C.D. Buxton, S.J. Campbell, A.T. Cooper, M. Davey, S.C. Edgar, G. Försterra, D.E. Galván, A.J. Irigoyen, D.J. Kushner, R. Moura, P.E. Parnell, N.T. Shears, G. Soler, E.M.A. Strain, R.J. Thomson, Global conservation outcomes depend on marine protected areas with five key features, Nature 506 (2014) 216-220,

http://dx.doi.org/10.1038/nature13022.

[23] D.J. McCauley, P. Woods, B. Sullivan, B. Bergman, C. Jablonicky, A. Roan, M. Hirshfield, K. Boerder, B. Worm, Ending hide and seek at sea, Science 351 (2016) 1148-1150.

[24] I. Urbina, A Renegade Trawler, Hunted for 10,000 Miles by Vigilantes, N. Y. Times. 〈http://www.nytimes.com/2015/07/28/world/a-renegade-trawler-hunted-for10000-miles-byvigilantes.html) (accessed 18 March 2016). 
[25] N.J. Bennett, H. Govan, T. Satterfield, Ocean grabbing, Mar. Policy 57 (2015) 61-68, http://dx.doi.org/10.1016/j.marpol.2015.03.026. [26] L. Richmond, D. Kotowicz, Equity and access in marine protected areas: the history and future of "traditional indigenous fishing" in the Marianas Trench Marine National Monument, Appl. Geogr. (2015), http://dx.doi.org/10.1016/j.apgeog.2014.11.007.

[27] R. Hilborn, Environmental cost of conservation victories, Proc. Natl. Acad. Sci. 110 (2013), http://dx.doi.org/10.1073/pnas.1308962110 9187-9187.

[28] P. Christie, Marine protected areas as biological successes and social failures in Southeast Asia, Am. Fish. Soc. Symp. 42 (2004) 155-164.

[29] M.B. Mascia, C.A. Claus, R. Naidoo, Impacts of marine protected areas on fishing communities, Conserv. Biol. 24 (2010) 1424-1429, http://dx.doi.org/10.1111/j.15231739.2010.01523.x.

[30] N.J. Bennett, P. Dearden, Why local people do not support conservation: community perceptions of marine protected area livelihood impacts, governance and management in Thailand, Mar. Policy 44 (2014) 107-116, http://dx.doi.org/10.1016/j.marpol.2013.08.017.

[31] T. Aulani Wilhelm, C.R.C. Sheppard, A.L.S. Sheppard, C.F. Gaymer, J. Parks, D. Wagner, N. Lewis, Large marine protected areas - advantages and challenges of going big, Aquat. Conserv. Mar. Freshw. Ecosyst. 24 (2014) 24-30, http://dx.doi.org/10.1002/aqc.2499.

[32] A.M. Friedlander, D. Wagner, C.F. Gaymer, T. Aulani Wilhelm, N. Lewis, S. Brooke, K. Kikiloi, O. Varmer, Co-operation between large-scale MPAs: successful experiences from the Pacific Ocean, Aquat. Conserv. Mar. Freshw. Ecosyst. 26 (2016) 126-141, http://dx.doi.org/10.1002/aqc.2645.

[33] Big Ocean, A shared research agenda for large-scale marine protected areas, Big Ocean, Honolulu, Hawaii, 2013.

[34] N.J. Bennett, R. Roth, S.C. Klain, K.M.A. Chan, D.A. Clark, G. Cullman, G. Epstein, M.P. Nelson, R.C. Stedman, T.L. Teel, R.E.W. Thomas, C. Wyborn, D. Curran, A. Greenberg, J. Sandlos, D. Veríssimo, Mainstreaming the social sciences in conservation, Conserv. Biol online, 2016.

[35] N.J. Bennett, R. Roth, S.C. Klain, K.M.A. Chan, P. Christie, D.A. Clark, G. Cullman, D. Curran, T.J. Durbin, G. Epstein, A. Greenberg, M.P. Nelson, J. Sandlos, R.C. Stedman, T.L. Teel, R.E.W. Thomas, D. Veríssimo, C. Wyborn, Conservation social science: understanding and integrating human dimensions to improve conservation, Biol. Conserv. 205 (2017) 93-108.

[36] N.J. Bennett, P. Dearden, From measuring outcomes to providing inputs: governance, management, and local development for more effective marine protected areas, Mar. Policy 50 (2014) 96-110, http://dx.doi.org/10.1016/j.marpol.2014.05.005. 
[37] J.E. Cinner, C. Huchery, M.A. MacNeil, N.A.J. Graham, T.R. McClanahan, J. Maina, E. Maire, J.N. Kittinger, C.C. Hicks, C. Mora, E.H. Allison, S. D’Agata, A. Hoey, D.A. Feary, L. Crowder, I.D. Williams, M. Kulbicki, L. Vigliola, L. Wantiez, G. Edgar, R.D. Stuart-Smith, S.A. Sandin, A.L. Green, M.J. Hardt, M. Beger, A. Friedlander, S.J. Campbell, K.E. Holmes, S.K. Wilson, E. Brokovich, A.J. Brooks, J.J. Cruz-Motta, D.J. Booth, P. Chabanet, C. Gough, M. Tupper, S.C.A. Ferse, U.R. Sumaila, D. Mouillot, Bright spots among the world's coral reefs, Nat. Adv. Online Publ. (2016), http://dx.doi.org/10.1038/nature18607.

[38] N.C. Ban, M. Mills, J. Tam, C.C. Hicks, S. Klain, N. Stoeckl, M.C. Bottrill, J. Levine, R.L. Pressey, T. Satterfield, K.M. Chan, A social-ecological approach to conservation planning: embedding social considerations, Front. Ecol. Environ. 11 (2013) 194-202, http://dx.doi.org/10.1890/110205.

[39] J.N. Kittinger, Human dimensions of small-scale and traditional fisheries in the Asia-Pacific Region, Pac. Sci. 67 (2013) 315-325.

[40] P. Christie, Creating space for interdisciplinary marine and coastal research: five dilemmas and suggested resolutions, Environ. Conserv. 38 (2011) 172-186, http://dx.doi.org/10.1017/S0376892911000129.

[41] B. Turner II, K.J. Esler, P. Bridgewater, J. Tewksbury, J.N. Sitas, B. Abrahams, F.S. Chapin, R.R. Chowdhury, P. Christie, S. Diaz, P. Firth, C.N. Knapp, J. Kramer, R. Leemans, M. Palmer, D. Pietri, J. Pittman, J. Sarukhán, R. Shackleton, R. Seidler, B. van Wilgen, H. Mooney, SocioEnvironmental Systems (SES) Research: what have we learned and how can we use this information in future research programs, Curr. Opin. Environ. Sustain. 19 (2016) 160-168, http://dx.doi.org/10.1016/j.cosust.2016.04.001.

[42] H. Bradbury, The SAGE Handbook of Action Research, SAGE, 2015.

[43] A.M. Meadow, D.B. Ferguson, Z. Guido, A. Horangic, G. Owen, T. Wall, Moving toward the deliberate coproduction of climate science knowledge, Weather Clim. Soc. 7 (2015) 179-191, http://dx.doi.org/10.1175/WCAS-D-14-00050.1.

[44] E. Wenger-Trayner, B. Wenger-Trayner, Introduction to communities of practice. $\langle$ http://wenger-trayner.com/introduction-to-communities-of-practice/〉 (accessed 13 September 2016).

[45] E. Wenger, Communities of practice and social learning systems, Organization 7 (2000) 225-246, http://dx.doi.org/10.1177/135050840072002.

[46] C.A. Maida, S. Beck, Towards communities of practice in global sustainability, Anthropol. Action 23 (2016) 1-5, http://dx.doi.org/10.3167/aia.2016.230101. 
[47] H.D. LSMPA, Community of Practice, A Practical Framework for Addressing the Human Dimensions of Large-Scale Marine Protected Areas, University of Washington, Seattle, WA, 2016 (available at), 〈https://smea.uw.edu/faculty/patrick-christie/〉.

[48] R.S. Pomeroy, J.E. Parks, L.M. Watson, How is your MPA doing?: a Guidebook of Natural and Social Indicators for Evaluating Marine Protected Area Management Effectiveness, IUCN, Gland, Switzerland, (2004).

[49] H.E. Fox, J.L. Holtzman, K.M. Haisfield, C.G. McNally, G.A. Cid, M.B. Mascia, J.E. Parks, R.S. Pomeroy, How are our MPAs doing? Challenges in Assessing global patterns in marine protected area performance, Coast. Manag. 42 (2014) 207-226, http://dx.doi.org/10.1080/08920753.2014.904178.

[50] A. White, P.M. Aliño, A. Meneses, Creating and Managing Marine Protected Areas in the Phillippines, Fisheries Improved for Sustainable Harvest Project, Coastal Conservation and Education Foundation and University of the Phillippines Marine Science Institute, Cebu City, Phillipines, 2006.

[51] A.T. White, P.M. Aliño, A. Cros, N.A. Fatan, A.L. Green, S.J. Teoh, L. Laroya, N. Peterson, S. Tan, S. Tighe, R. Venegas-Li, A. Walton, W. Wen, Marine protected areas in the Coral Triangle: progress, issues, and options, Coast. Manag. 42 (2014) 87-106, http://dx.doi.org/10.1080/08920753.2014.878177.

[52] R.V. Salm, J.R. Clark, E. Siirila, Marine and Coastal Protected Areas: A Guide for Planners and Managers, IUCN, Gland, Switzerland, 2000.

[53] P. Christie, A. White, Best practices for improved governance of coral reef marine protected areas, Coral Reefs 26 (2007) 1047-1056, http://dx.doi.org/10.1007/s00338-0070235-9.

[54] FAO, Report and Documentation of the Expert Workshop on Marine Protected Areas and Fisheries Management: Review of Issues and Considerations, Rome, 12-14 June 2006, FAO/Japan Government Cooperative Programme, Rome, 2007.

[55] N.C. Ban, V.M. Adams, G.R. Almany, S. Ban, J.E. Cinner, L.J. McCook, M. Mills, R.L. Pressey, A. White, Designing, implementing and managing marine protected areas: emerging trends and opportunities for coral reef nations, J. Exp. Mar. Biol. Ecol. 408 (2011) 21-31, http://dx.doi.org/10.1016/j.jembe.2011.07.023.

[56] J.M. Burt, P. Akins, E. Latham, B. Martina, A.K. Salomon, N.C. Ban, Marine Protected Area Network Design Features that Support Resilient Human-Ocean Systems, Simon Fraser University, Vancouver, Canada, 2015. 
[57] N. Lewis, J. Day, D. Wagner, C.F. Gaymer, A. Friedlander, J. Parks, T. Aulani Wilhelm, S. White, C. Sheppard, M. Spalding, S. Brooke, H. Hirsh, G. San Martin, A. Skeat, S. Taei, T.

Teroroko, J. Evans, Guidelines for the Design and Management of Large-Scale Marine Protected Areas, IUCN/CBD/Big Ocean, Gland, Switzerland, 2016.

[58] C. Pala, Tracking fishy behavior, from space, The Atlantic.

〈http://www.theatlantic.com/technology/archive/2014/11/tracking-fishy-behaviorfromspace/382797/> (accessed 18 March 2016).

[59] L.J. McCook, T. Ayling, M. Cappo, J.H. Choat, R.D. Evans, D.M.D. Freitas, M. Heupel, T.P. Hughes, G.P. Jones, B. Mapstone, H. Marsh, M. Mills, F.J. Molloy, C.R. Pitcher, R.L. Pressey, G.R. Russ, S. Sutton, H. Sweatman, R. Tobin, D.R. Wachenfeld, D.H. Williamson, Adaptive management of the Great Barrier Reef: a globally significant demonstration of the benefits of networks of marine reserves, Proc. Natl. Acad. Sci. 107 (2010) 18278-18285, http://dx.doi.org/10.1073/pnas.0909335107.

[60] J.N. Kittinger, A. Dowling, A.R. Purves, N.A. Milne, P. Olsson, Marine protected areas, multiple-agency management, and monumental surprise in the Northwestern Hawaiian Islands, J. Mar. Biol. 2011 (2011).

[61] J.C. Day, K. Dobbs, Effective governance of a large and complex cross-jurisdictional marine protected area: Australia's Great Barrier Reef, Mar. Policy 41 (2013) 14-24, http://dx.doi.org/10.1016/j.marpol.2012.12.020.

[62] Q. Schiermeier, World's largest marine reserve hailed as diplomatic breakthrough, Nat. News 539 (2016) 13, http://dx.doi.org/10.1038/nature.2016.20900.

[63] J.G. Hastings, Building participation in large-scale conservation: lessons from Belize and Panama, Conserv. Soc. 13 (2015) 221.

[64] J.A. Aburto, C.F. Gaymer, G. Cundill, Towards local governance of marine resources and ecosystems on Easter Island, Aquat. Conserv. Mar. Freshw. Ecosyst. (2016), http://dx.doi.org/10.1002/aqc.2665.

[65] P. Christie, N.J. Bennett, T. 'Aulani. Wilhelm, N. Lewis, D. Wagner, N. Ban, N. Gray, R.L. Gruby, Proposal for a "Think Tank" on the Human Dimensions of Large-Scale Marine Protected Areas, 2015.

[66] C. Sandbrook, W.M. Adams, B. Büscher, B. Vira, Social research and biodiversity conservation, Conserv. Biol. 27 (2013) 1487-1490, http://dx.doi.org/10.1111/cobi.12141.

[67] P. Christie, B.J. McKay, M.L. Miller, C. Lowe, A.T. White, R. Stoffle, D.L. Fluharty, L.T. McManus, R. Chuenpagdee, C. Pomeroy, D.O. Suman, B.G. Blount, D. Huppert, R. Elsma, E. 
Oracion, K. Lowry, R.B. Pollnac, Toward developing a complete understanding: a social science research agenda for marine protected areas, Fisheries 28 (2003) 22-26.

[68] N.J. Bennett, L. Teh, Y. Ota, P. Christie, A. Ayers, J.C. Day, P. Franks, D. Gill, R.L. Gruby, J.N. Kittinger, J.Z. Koehn, N. Lewis, J. Parks, M. Vierros, T.S. Whitty, A. Wilhelm, K. Wright, J.A. Aburto, E.M. Finkbeiner, C.F. Gaymer, H. Govan, N. Gray, R.M. Jarvis, M. Kaplan-Hallam, T. Satterfield, An appeal for a code of conduct for marine conservation, Mar. Policy 81 (2017) 411-418, http://dx.doi.org/10.1016/j.marpol.2017.03.035.

[69] N.J. Gray, N.J. Bennett, J. Day, R.L. Gruby, T.'Aulani Wilhelm, P. Christie, Human dimensions of large-scale marine protected areas: Advancing research and practice, Coast. Manag. (in press).

[70] C. Watkins, J. Zavaleta, S. Wilson, S. Francisco, Developing an interdisciplinary and crosssectoral community of practice in the domain of forests and livelihoods (early view online), Conserv. Biol. (2017), http://dx.doi.org/10.1111/cobi.12982.

[71] R.L. Gruby, L.W. Fairbanks, L. Acton, E. Artis, L.M. Campbell, N.J. Gray, L. Mitchell, S.B.J. Zigler, K. Wilson, Conceptualizing social outcomes of large marine protected areas, Coast. Manag. (in press). 